\title{
SURVEY
}

\section{Parental Attitude towards the Provision of Non- surgical Oral Health Care to Children with Oral Clefts: An Epidemiological Survey}

\author{
${ }^{1}$ Manju Gopakumar, ${ }^{2}$ Amitha M Hegde \\ ${ }^{1}$ Reader, Department of Pedodontics and Preventive Children Dentistry, AB Shetty Memorial Institute of Dental Sciences Man- \\ galore, Karnataka, India \\ ${ }^{2}$ Professor and Head, Department of Pedodontics and Preventive Children Dentistry, AB Shetty Memorial Institute of Dental \\ Sciences, Mangalore, Karnataka, India
}

Correspondence: Manju Gopakumar, Reader, Department of Pedodontics and Preventive Children Dentistry, AB Shetty Memorial Institute of Dental Sciences, Mangalore, Karnataka, India, e-mail: gopsmanju @ yahoo.co.in

\begin{abstract}
Aim : To evaluate the attitudes of parents of 3 to 8 years old children with cleft lip and palate towards the provision of pediatric dental health care and assess the experience of dentistry in general dental practice.

Materials and methods : A questionnaire was distributed to parents of 100 children in the age group of 3 to 8 years old with cleft lip and palate who visited the cleft lip and palate center in KS Hegde Medical Academy, Mangalore.

Results : Out of the hundred patients, $66 \%$ of the patients registered directly at the cleft center for their deformity. Only $20 \%$ of these children visited a local dental practitioner for their dental health care. $42 \%$ had neither undergone any dental treatment nor received any dietary or oral hygiene advices. Regarding the provision of the dental treatment, $74 \%$ wanted a pediatric dentist to provide dental check-up and treatment at the cleft center, whereas, $24 \%$ preferred a dental practitioner close to their home and $2 \%$ does not want treatment anywhere.

Conclusion : The survey indicates that there is parental support for the pediatric dental assessment at the cleft center with subsequent arrangement of dental treatment with their local dental practitioners. The majority wanted a pediatric dentist to provide the dental check-up and treatment at the cleft center.
\end{abstract}

Keywords : Cleft lip/palate, dental treatment, parental attitude.

\section{INTRODUCTION}

Good and healthy children of today, make the better, strong and healthy parents of tomorrow. But, the environment within which the children are being raised is changing due to various reasons like single parent families, working mothers with diverse arrangements for childcare, continued poverty and increased incidence of child abuse and neglect. In such a world, the major brunt of responsibility to help these neglected children falls on the doctor's shoulders. The condition of these children worsens when they are born with anomalies like the orofacial clefts. No congenital anomaly has more complexity and diverse morphological influence in the oral and maxillofacial region than the cleft of the lip and palate (CLP). It has an occurrence of 1 in 800 to 1000 live births and is the most common congenital facial anomaly. ${ }^{1}$ Studies have shown that children with CLP have poor dental health than children in the general population. $^{2-4}$

Achieving optimal dental health may be difficult due to anatomy of the cleft area, malaligned teeth, hypoplastic defects and scarring. ${ }^{2}$ Children with CLP tend to have poorer oral and gingival health compared with those with isolated cleft of the lip or palate. ${ }^{5}$

The special needs of the children with CLP have been recognized by the Clinical Standards Advising Group (CSAG). Their report recommended that preventive advice should be given to the parents of newly born cleft children within one year and pediatric dental services provided throughout childhood and adolescence. ${ }^{6}$

As the incidence of cleft lip is only $1 / 800$ live births, a general dental practitioner may have limited experience in treating these patients ${ }^{7}$ and as a result may encounter more 
management problems. ${ }^{8}$ As a member of the cleft team, a pediatric dentist can provide preventive programs and dietary advice to cleft lip and palate children which have shown to reduce dental caries ${ }^{9}$ and thus be cost effective. ${ }^{10}$

The aim of the study was to evaluate the attitudes of the parents of the children with CLP towards the provision of pediatric dental care and to assess their experience of dentistry in general dental practice.

\section{SUBJECTS AND METHODS}

A structured questionnaire was given to the parents of hundred children who visited the cleft lip center in KS Hegde Medical Academy, Mangalore. The children were in the age group of 3 to 8 years. The lower age limit was chosen because it was felt that many children under the age of 4 years might not be registered with a dentist. The upper age limit was chosen as 8 years to assess the attitudes and experiences prior to the first orthodontic intervention of maxillary expansion, which is undertaken in many children with CLP prior to bone grafting at 8 to 9 years.

\section{RESULTS}

Out of the hundred patients, 34\% had first registered with a local dental practitioner for their cleft deformity and were then referred to the cleft center. $66 \%$ of the patients registered directly at the cleft center for their deformity. Only $20 \%$ of these children visited a local dental practitioner for their dental health care.

On evaluation of the previous dental visits, $42 \%$ had not undergone any dental treatment and received any dietary or oral hygiene advices. While, $38 \%$ of children had received dietary advice as well as general oral hygiene measures, $16 \%$ given tooth brushing instructions and $4 \%$ of the children who experienced restorative interventions (Table 1).

On assessing parental awareness regarding the treatment needs of these children, $20 \%$ of the parents were not willing to receive dietary advice or oral hygiene measures. $16 \%$ of the parents were aware regarding the various treatment modalities available to these children. $6 \%$ of the parents were apprehensive regarding the surgical correction of defects and another $30 \%$ of the parents were apprehensive about the speech problem of the child in the future. $28 \%$ of the parents knew that the speech problems could be corrected by speech therapy (Table 2 ).
Table 1: Previous dental visit and patient response in the present study

$\begin{array}{lc}\text { Previous dental visits } & \text { Patient response (\%) } \\ \text { No advice on diet oral hygiene } & 42 \\ \text { Received dietary advice and general } & \\ \text { oral hygiene measures } & 38 \\ \text { Tooth brushing instructions } & 16 \\ \text { Restoration } & 4\end{array}$

Table 2: Parental awareness regarding the various treatment needs

\section{Treatment needs}

Patient response (\%)

Not dietary advice
Various treatment modalities
Surgical correction of the defects
Speech problems
Speech therapy

$20 \%$

$16 \%$

$6 \%$

$30 \%$

$28 \%$

Regarding the provision of the dental treatment, 74\% wanted a pediatric dentist to provide dental check-up and treatment at the cleft center, whereas, $24 \%$ preferred a dental practitioner close to their home and $2 \%$ does not want treatment anywhere (Graph 1).

\section{DISCUSSION}

The provision of good pediatric dental care for children with cleft lip and palate is essential for this group of vulnerable patients. Although, coordination of care has been proposed by the cleft team, this is dependent on patients being able to access dental services in their locality. The present survey found that $34 \%$ of the children were registered with a dental practitioner and $66 \%$ of the children directly with the cleft center which does not follow the Clinical Standards Advising Group 1998, where 91\% of children registered with a dental practitioner. ${ }^{6}$

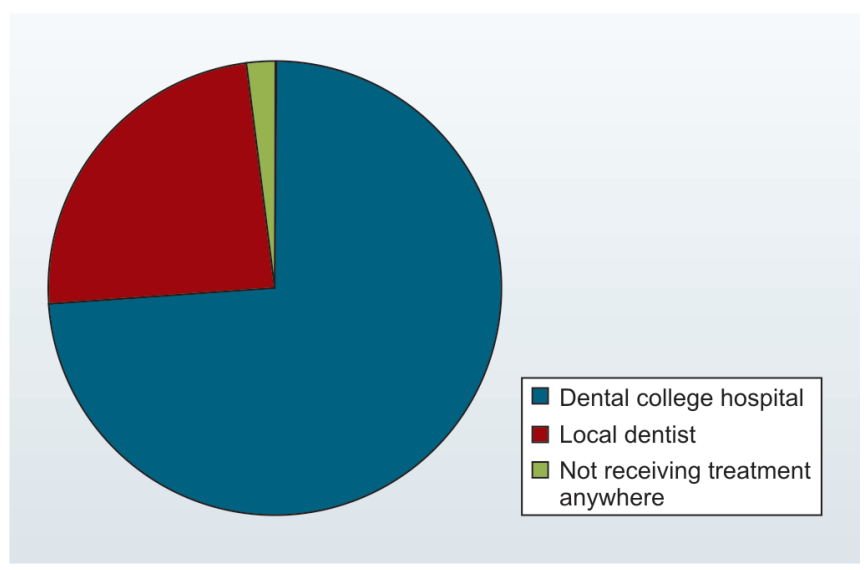

Graph 1: Provision of dental treatment 
In our survey, the parents of children with CLP were not much aware of the treatment needs of children, with only $16 \%$ of parents who knew the various dental treatment modalities that could be availed. Only $16 \%$ of children had received tooth brushing instruction which is very less compared to the study done by S Mc Donagh. ${ }^{11} 38 \%$ of children received dietary advice as well as general oral hygiene measures which again was found to be very less when compared to the study done by S Mc Donagh. ${ }^{11}$ From this survey it was found that a sizeable proportion $(61 \%)$ of parents of children with CLP had not received any dental health advice.

Regarding the provision of dental examination and treatment $74 \%$ wanted the pediatric dentist to have a dental examination and treatment at the cleft center, whereas $24 \%$ preferred by a local dental practitioner. This was in agreement with the survey done by S Mc Donagh et al. ${ }^{11}$

The inclusion of pediatric dental support in the cleft team to identify 'at risk' patients and facilitate the provision of care services through hospitals, community, and a general dental practitioner has been shown to be effective. This survey indicates that, there is parental support for the provision of pediatric dental assessment at the cleft center, though they prefer subsequent care with their local dental practitioners. As a pediatric dentist, we can provide anticipatory guidance to parents of these children at dental home in the cleft center. Thus, the pediatric dentist play a pivotal role as a part of the cleft team in preventing and managing dental disease and malocclusion and laying the foundation of overall health and nutrition for CLP children.

\section{CONCLUSION}

Most parents of children with CLP prefer dental examination and preventive advices provided at the cleft center. They majorly wanted a pediatric dentist to provide the dental check-up and treatment at the cleft center.

\section{REFERENCES}

1. Hudson JW. Oral and maxillofacial clinics of North America 2000;12(3):17.

2. Johnsen DC, Dixon M. Dental caries of primary incisors in children with cleft lip and palate. Cleft palate J 1984 Apr;21(2):104109.

3. Dahloff G, Ussisoo-Joandi R, Ideberg M, Modeer T. Caries, gingivitis and dental abnormalities in preschool children with cleft lip and/or palate. Cleft palate J 1989 Jul;26(3):233-237.

4. Ishida R, Yasafuku Y, Miyamoto A, Ooshima T, Sobue S. Clinical survey of caries incidence in the children with cleft lip and palate. Shoni Shikagaku Zasshi 1989;27(3):716-724. (Jpn).

5. Paul T, Brandt RS. Oral and dental health status of children with cleft lip and/or palate. Cleft Palate Craniofac J 1998 Jul;35(4):329-332.

6. Clinical Standards Advisory Group 1998. Cleft lip and /or palate. London: The Stationery office. Series no. HSE1998/002.

7. Pannbacker M, Lass NJ, Starr P. Information and experience with cleft palate: students, parents, professionals. Cleft Palate J 1979 Apr;16(2):198-205.

8. Dabed CC, Cauvi DL. Survey of dentist's experience with cleft palate children in Chile. Cleft Palate Craniofac J 1998 Sep;35(5):430-433.

9. Gregg TA, Johnston D, Pattison KE. Efficacy of specialist care for caries in the cleft child. Int J Paed Dent 1999;9(Suppl.):61.

10. Stephen KW, Mac Fayden EE. Three years of clinical caries prevention for cleft palate children. Br Dent J 1977 Aug;143(4):111116.

11. McDonagh S, Pinson R, Shaw AJ. Provision of general dental care for children with cleft lip and palate-parental attitudes and experiences. Br Dent J 2000 Oct;189(8):432-443. 